\title{
Article \\ Molecular Signatures of Natural Killer Cells in CMV-Associated Anterior Uveitis, A New Type of CMV-Induced Disease in Immunocompetent Individuals
}

\author{
Nobuyo Yawata ${ }^{1,2,3, *,+}$, Mariko Shirane ${ }^{4,+}$, Kaing Woon ${ }^{2}$, Xinru Lim ${ }^{2}$, Hidenori Tanaka 5 (D), Yoh-Ichi Kawano ${ }^{6}$, \\ Makoto Yawata $7,8,9,10,11,12$, Soon-Phaik Chee $2,3,13,14$, Jay Siak $2,3,13,14,+$ and Koh-Hei Sonoda ${ }^{4,+}$
}

Citation: Yawata, N.; Shirane, M.; Woon, K.; Lim, X.; Tanaka, H.; Kawano, Y.-I.; Yawata, M.; Chee, S.-P.; Siak, J.; Sonoda, K.-H. Molecular Signatures of Natural Killer Cells in CMV-Associated Anterior Uveitis, A New Type of CMV-Induced Disease in Immunocompetent Individuals. Int. J. Mol. Sci. 2021, 22, 3623. https://doi.org/10.3390/ ijms 22073623

Academic Editor: Sunao Sugita

Received: 28 February 2021

Accepted: 29 March 2021

Published: 31 March 2021

Publisher's Note: MDPI stays neutral with regard to jurisdictional claims in published maps and institutional affiliations.

Copyright: (c) 2021 by the authors. Licensee MDPI, Basel, Switzerland. This article is an open access article distributed under the terms and conditions of the Creative Commons Attribution (CC BY) license (https:// creativecommons.org/licenses/by/ $4.0 /)$.
1 Department of Ocular Pathology and Imaging Science, Kyushu University, Fukuoka 812-8582, Japan

2 Singapore Eye Research Institute, Singapore 168751, Singapore; woonkaing@gmail.com (K.W.); limxr@imcb.a-star.edu.sg (X.L.); chee.soon.phaik@singhealth.com.sg (S.-P.C.); jay.siak.j.k@singhealth.com.sg (J.S.)

3 Ophthalmology and Visual Sciences Academic Clinical Program, Duke-NUS Medical School, Singapore 169857, Singapore

4 Department of Ophthalmology, Kyushu University, Fukuoka 812-8582, Japan; marikoshirane22@gmail.com (M.S.); sonodak@med.kyushu-u.ac.jp (K.-H.S.)

$5 \quad$ HLA Foundation Laboratory, Kyoto 600-8813, Japan; h-tanaka@hla.or.jp

6 Department of Ophthalmology, Fukuoka Dental College, Fukuoka 814-0193, Japan; ykawano@college.fdcnet.ac.jp

7 Singapore Institute for Clinical Sciences (SICS), Agency for Science, Technology and Research, A*STAR, Singapore 117609, Singapore; paeym@nus.edu.sg

8 Department of Pediatrics, Yong Loo Lin School of Medicine, National University of Singapore, Singapore 119228, Singapore

9 National University Health System, Singapore 119228, Singapore

10 Immunology Programme, Life Sciences Institute, National University of Singapore, Singapore 117456, Singapore

11 NUSMED Immunology Translational Research Programme, National University of Singapore, Singapore 117456, Singapore

12 International Research Center for Medical Sciences, Kumamoto University, Kumamoto 860-8555, Japan

13 Department of Ophthalmology, Yong Loo Lin School of Medicine, National University of Singapore, Singapore 119228, Singapore

14 Ocular Inflammation and Immunology Department, Singapore National Eye Centre, Singapore 168751, Singapore

* Correspondence: yawata.nobuyo.718@m.kyushu-u.ac.jp

$\dagger$ These authors contributed equally to this work.

Abstract: Cytomegalovirus (CMV) causes clinical issues primarily in immune-suppressed conditions. $\mathrm{CMV}$-associated anterior uveitis (CMV-AU) is a notable new disease entity manifesting recurrent ocular inflammation in immunocompetent individuals. As patient demographics indicated contributions from genetic background and immunosenescence as possible underlying pathological mechanisms, we analyzed the immunogenetics of the cohort in conjunction with cell phenotypes to identify molecular signatures of CMV-AU. Among the immune cell types, natural killer (NK) cells are main responders against CMV. Therefore, we first characterized variants of polymorphic genes that encode differences in CMV-related human NK cell responses (Killer cell Immunoglobulin-like Receptors (KIR) and HLA class I) in 122 CMV-AU patients. The cases were then stratified according to their genetic features and NK cells were analyzed for human CMV-related markers (CD57, KLRG1, NKG2C) by flow cytometry. KIR3DL1 and HLA class I combinations encoding strong receptor-ligand interactions were present at substantially higher frequencies in CMV-AU. In these cases, NK cell profiling revealed expansion of the subset co-expressing CD57 and KLRG1, and together with KIR3DL1 and the CMV-recognizing NKG2C receptor. The findings imply that a mechanism of CMV-AU pathogenesis likely involves CMVresponding NK cells co-expressing CD57/KLRG1/NKG2C that develop on a genetic background of KIR3DL1/HLA-B allotypes encoding strong receptor-ligand interactions. 
Keywords: cytomegalovirus; cytomegalovirus-associated anterior uveitis; killer cell immunoglobulinlike receptors; HLA class I; natural killer cells; CD57; KLRG1; NKG2C

\section{Introduction}

Human cytomegalovirus (HCMV) causes latent infection in 50-90\% of global populations and is prevalent especially in Asian populations [1]. Various mechanisms have been proposed to explain how CMV evades immune responses to maintain latent infection, resulting in recurrent, asymptomatic, subclinical reactivation of CMV [2]. The clinical manifestations of latent CMV infection are thought to occur primarily in severely immunocompromised individuals, such as in those with Acquired Immunodeficiency Syndrome and patients who are undergoing transplantation [3]. In the field of ophthalmology, CMV retinitis has been well-documented in these conditions [4]. However, the recent, newly established entity of CMV-anterior uveitis (CMV-AU) is noteworthy in that recurrent, intraocular inflammation is induced by CMV in individuals without apparent immunodeficiency or immune suppression [5,6]. Furthermore, newly developed, high-sensitivity, PCR-based detection methods have revealed that CMV is likely the most frequent cause of virus-induced anterior uveitis in Chinese and Japanese populations [7,8]. In terms of treatments for CMV-AU, topical combination therapy with the anti-viral drug ganciclovir and corticosteroids is effective; however, the inflammation recurs if treatment is discontinued [9]. This observation implies that the pathogenesis of CMV-AU likely involves dysregulation of the host immunity that controls CMV reactivation.

Studies on the immunological mechanisms of CMV infection have focused primarily on either severely immunocompromised cases or healthy human controls. The reasons are yet unclear as to why some individuals without apparent immunosuppression develop recurrent, CMV-induced ocular inflammation. CMV-AU is prevalent in Asian populations and occurs primarily in individuals who are middle-aged and older $[7,10]$. These clinical observations suggest that genetic factors combined with the consequences of immunological senescence are critical factors in the pathological mechanism in this disease. Based on this hypothesis, we designed this study to investigate genetic factors and immunological senescence in natural killer (NK) cells, which have been identified as major responders in the immune response against CMV [11,12].

The functions of NK cells differ substantially among human individuals [13], where cellular responses are regulated via the interactions between Killer cell Immunoglobulinlike Receptors (KIRs) and their cognate ligands, HLA class I. In contrast to CD8 ${ }^{+} \mathrm{T}$ cells, which are stimulated by upregulated expression of HLA class I, NK cells are activated by downregulation of HLA class I, namely the 'missing-self response', which is an immune response unique to NK cells. This has relevance in infection or malignant transformation where HLA class I molecules will often become downregulated [14]. Furthermore, the genetic polymorphisms in KIRs and HLA class I have been demonstrated to differentiate the strength of missing-self responses; the concept of 'NK cell education' or 'licensing' [15-18]. Therefore, inherited KIR and HLA class I polymorphisms are directly responsible for differences in cytotoxic and pro-inflammatory NK cell responses [13,19].

The two main modes of immunological escape by CMV involve either (1) downregulation of HLA-A and HLA-B in infected cells, or (2) loading of peptides derived from a CMV-encoded protein, UL40, onto HLA-E [20-22]. The former mechanism results in loss of cytotoxic T cell responses; however, in this situation, the host can still respond against CMV-infected cells through NK cell responses mediated by the missing-self mechanism [14]. Of relevance to this study is the extensive variability in the genes that confer individuality to NK cell licensing and the anti-CMV response: HLA class I and the KIR (KIR3DL1 in particular in this study). KIR3DL1 recognizes only the HLA-B allotypes with a Bw4 motif (approximately $1 / 3$ of the HLA-B allotypes); therefore, the induction of 
NK cell missing-self responses via this mechanism depends on the $H L A-B$ alleles of the individual [17].

In the latter mechanism of immune evasion, the responses of NK cell subpopulations expressing the HLA-E specific inhibitory receptor NKG2A are suppressed [20-22]. In this situation, the presence of NK cells expressing the HLA-E binding-activating NKG2C receptor is of importance in CMV infection, where NKG2C binds to the HLA-E/UL40 complex to initiate anti-virus NK cell responses. The NKG2C-positive NK cell subpopulation is apparently expanded permanently in CMV-seropositive individuals; thus, the presence of this expanded subset in peripheral blood has been considered a hallmark of past CMV infection [23]. Such alterations to otherwise stable NK cell repertoire structures have been reported for several types of virus infections, such as those by human immunodeficiency virus, and the changes imply substantial involvement of NK cells in the anti-virus immune response [24]. One goal of this study was to identify this immunological signature in CMV-AU cases.

We hypothesized that there may be some features in KIR-HLA genetics as a background condition, and secondly that the recurrent inflammation characteristic of CMV-AU is triggered by dysregulated NK cell functions. To investigate these questions, we first stratified the cases according to genetic factors with the most potential to alter human NK cell function, and then studied NK cell differentiation markers in CMV-AU blood specimens. We then characterized the genetic polymorphisms of HLA class I and KIR in $122 \mathrm{CMV}-\mathrm{AU}$ cases and integrated the data with NK cell phenotype analyses. Our findings suggest a role for NK cells co-expressing CD57, KLRG1, and NKG2C that have developed on a genetic background of KIR3DL1/HLA-B allotypes encoding strong receptor-ligand interactions, in CMV-AU pathogenesis.

\section{Results}

\subsection{Polymorphisms of KIRs and Their Ligands Associated with CMV-AU}

KIR and HLA class I genotypes were characterized in 122 CMV-AU cases, and the profiles were compared with those of 208 healthy individuals of the same ethnicity (Chinese Singaporean) [25] (Figure 1a). Eighteen KIR genotypes were identified in the CMV-AU cases, six of which were present only in CMV-AU. In contrast, 14 of the 26 KIR genotypes present in healthy controls were not found in CMV-AU. No apparent association of individual KIR genes with CMV-AU was detected in this study (Figure 1b).

In the human genome, the 16 KIR genes cluster in one area of chromosome 19 where the genome structure is highly variable, resulting in many haplotypes carrying different combinations of KIR gene loci [27]. In the context of anti-CMV NK cell responses, KIR2DL1, KIR2DL2, KIR2DL3, and KIR3DL1 are of importance due to their roles in programming missing-self NK responses, the concept of NK cell education, or licensing [15-17]. Whereas many KIR haplotypes carry various combinations of these four KIR genes (in addition to others), one particular haplotype-the group $A$ KIR haplotype with a fixed set of seven KIR genes containing KIR2DL1, KIR2DL3, and KIR3DL1 - was of particular interest in our study, as this $A$ haplotype is present at a high frequency in East Asian populations [29,30]. All other combinations of KIR genes are collectively termed group $B$ KIR haplotypes [18]. However, in this study, no apparent association between group A KIR haplotypes (51.6\% homozygotes in CMV-AU, 55.3\% in the healthy controls) and CMV-AU was detected (Figure 1a,b). 
(a)

\begin{tabular}{|c|c|c|c|c|c|c|c|c|c|c|c|c|c|c|c|c|c|}
\hline \multirow[b]{2}{*}{$\#$} & \multirow{2}{*}{ Haplogroup } & \multirow{2}{*}{ Cent-Tel } & \multicolumn{4}{|c|}{ Centromeric } & \multicolumn{3}{|c|}{ Either } & \multicolumn{4}{|c|}{ Telomeric } & \multicolumn{2}{|c|}{ CMV-AU } & \multicolumn{2}{|c|}{ Controls } \\
\hline & & & $2 D L 3$ & $2 D L 1$ & $2 D S 2$ & $2 D L 2$ & $2 D L 5$ & $2 D S 3$ & $2 D S 5$ & $3 D L 1$ & $2 D S 4$ & $3 D S 1$ & 2DS1 & $\mathbf{n}$ & $(\%)$ & $\mathbf{n}$ & (\%) \\
\hline 1 & $\overline{A A}$ & $A A-A A$ & & & & & & & & & & & & 63 & 51.6 & 115 & 55.3 \\
\hline 2 & $B x$ & $A A-A B$ & & & & & & & & & & & & 18 & 14.8 & 22 & 10.6 \\
\hline 3 & $B x$ & $A A-A B$ & & & & & & & & & & & & 8 & 6.6 & 17 & 8.2 \\
\hline 4 & $B x$ & $A B-A A$ & & & & & & & & & & & & 5 & 4.1 & 9 & 4.3 \\
\hline 5 & $B x$ & $A B-A B$ & & & & & & & & & & & & 5 & 4.1 & 5 & 2.4 \\
\hline 6 & $B x$ & $A B-A B$ & & & & & & & & & & & & 4 & 3.3 & 3 & 1.4 \\
\hline 7 & $B x$ & $A B-A A$ & & & & & & & & & & & & 3 & 2.5 & 10 & 4.8 \\
\hline 8 & $B x$ & $A B-A B$ & & & & & & & & & & & & 4 & 3.3 & 1 & 0.5 \\
\hline 9 & $B x$ & $A B-A B$ & & & & & & & & & & & & 2 & 1.6 & 2 & 1 \\
\hline 10 & $B x$ & $B B-A B$ & & & & & & & & & & & & 2 & 1.6 & 0 & 0 \\
\hline 11 & $B x$ & $A B-B B$ & & & & & & & & & & & & 1 & 0.8 & 2 & 1 \\
\hline 12 & $B x$ & $A A-B B$ & & & & & & & & & & & & 1 & 0.8 & 1 & 0.5 \\
\hline 13 & $B x$ & $B B-A A$ & & & & & & & & & & & & 1 & 0.8 & 1 & 0.5 \\
\hline 14 & $B x$ & $A B-A B$ & & & & & & & & & & & & 1 & 0.8 & 0 & 0 \\
\hline 15 & $B x$ & $A B-B B$ & & & & & & & & & & & & 1 & 0.8 & 0 & 0 \\
\hline 16 & $B x$ & $B B-A B$ & & & & & & & & & & & & 1 & 0.8 & 0 & 0 \\
\hline 17 & $B x$ & $A A-B B$ & & & & & & & & & & & & 1 & 0.8 & 0 & 0 \\
\hline 18 & $B x$ & $A B-A B$ & & & & & & & & & & & & 1 & 0.8 & 0 & 0 \\
\hline 19 & $B x$ & $A B-A B$ & & & & & & & & & & & & 0 & 0.0 & 3 & 1.4 \\
\hline 20 & $B x$ & $A A-B B$ & & & & & & & & & & & & 0 & 0.0 & 3 & 1.4 \\
\hline 21 & $B x$ & $A A-A B$ & & & & & & & & & & & & 0 & 0.0 & 2 & 1 \\
\hline 22 & $B x$ & $B B-B B$ & & & & & & & & & & & & 0 & 0.0 & 2 & 1 \\
\hline 23 & $B x$ & $A A-A B$ & & & & & & & & & & & & 0 & 0.0 & 1 & 0.5 \\
\hline 24 & $B x$ & $A A-A B$ & & & & & & & & & & & & 0 & 0.0 & 1 & 0.5 \\
\hline 25 & $B x$ & $A A-A B$ & & & & & & & & & & & & 0 & 0.0 & 1 & 0.5 \\
\hline 26 & $B x$ & $A A-A B$ & & & & & & & & & & & & 0 & 0.0 & 1 & 0.5 \\
\hline 27 & $B x$ & $A A-B B$ & & & & & & & & & & & & 0 & 0.0 & 1 & 0.5 \\
\hline 28 & $B x$ & $A B-A A$ & & & & & & & & & & & & 0 & 0.0 & 1 & 0.5 \\
\hline 29 & $B x$ & $A B-B B$ & & & & & & & & & & & & 0 & 0.0 & 1 & 0.5 \\
\hline 30 & $B x$ & $A B-B B$ & & & & & & & & & & & & 0 & 0.0 & 1 & 0.5 \\
\hline 31 & $B x$ & $B B-A B$ & & & & & & & & & & & & 0 & 0.0 & 1 & 0.5 \\
\hline 32 & $B x$ & $B B-A B$ & & & & & & & & & & & & 0 & 0.0 & 1 & 0.5 \\
\hline
\end{tabular}

(b)

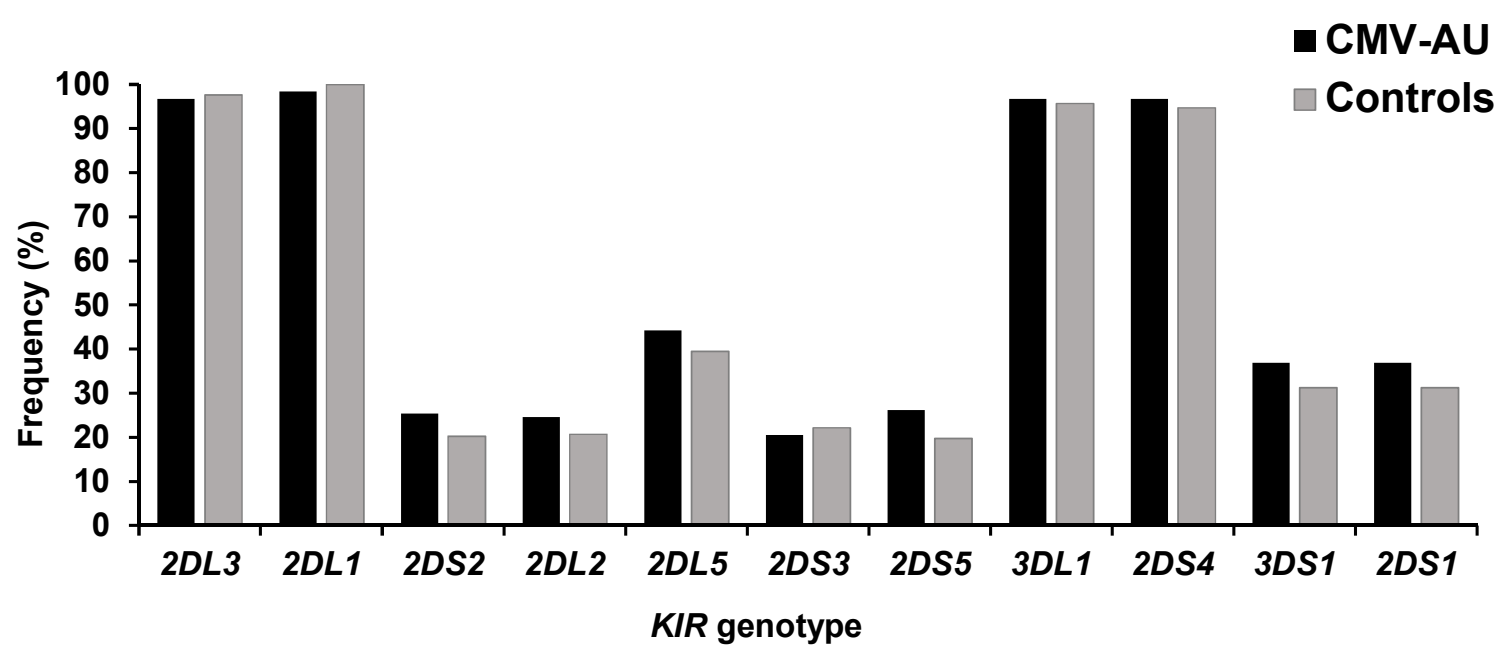

Figure 1. KIR genotypes in CMV-associated anterior uveitis (CMV-AU) patients and healthy controls. KIR genotypes (a) and gene frequencies (b) were determined in 122 individuals with CMV-AU. As a control, KIR genotypes in 208 healthy individuals of the same ethnicity (Chinese Singaporean) are shown from a previous study [25]. CMV-seropositivity was $87 \%$ based on a previous study in this population [26]. (a) Shaded boxes indicate presence of KIR genes. The centromeric/telomeric position of KIR loci indicated in columns 4 and 6 are their physical location within the KIR complex on chromosome 19 [27,28]. KIR2DL5, KIR2DS3, and KIR2DS5 genes can locate on either centromeric/telomeric sides of the KIR complex and are thus indicated in this table as such (column 5). KIR B haplotype-specific KIR genes are shown in red. $K I R$ framework genes and pseudogenes are excluded. (b) Black and gray boxes indicate each KIR genotype frequency in CMV-AU and healthy controls, respectively. 
We next applied the classification of KIR haplotype blocks that have proven useful in allogeneic bone marrow transplantation as surrogate predictors of NK cell alloreactivity [31]. In this system, fixed sets of KIR genes in linkage disequilibrium on the haplotypes are classified into centromeric and telomeric KIR genomic motifs [31]. This classification enables a rough estimation of the activation potential of NK cells in the individual based on the tendency of KIR B haplotypes to carry a higher frequency of activating KIR genes.

The KIR genotypes in the CMV-AU cohort were assigned KIR haplotype block groupings based on whether the genotypes contained genome segments derived from $A$ or $B$ haplotypes in the centromeric (Cen) or telomeric (Tel) sides of the KIR gene complex on chromosome 19 (Table 1, details in Methods section). This classification revealed a significantly higher frequency of the Cen- $A B+$ Tel- $A B$ KIR motif groups (heterozygous for groups $A$ and $B$ haplotype blocks on both the centromeric and telomeric KIR genes) in the CMV-AU cases compared with the healthy controls.

Table 1. Comparison of B-content score-based KIR haplotype motifs between CMV-AU and healthy controls.

\begin{tabular}{|c|c|c|c|c|c|c|c|}
\hline \multirow{2}{*}{$\begin{array}{c}\text { Haplotype } \\
\text { Group }\end{array}$} & \multirow{2}{*}{$\begin{array}{c}\text { B Content } \\
\text { Score }\end{array}$} & \multicolumn{2}{|c|}{ Motif } & \multicolumn{2}{|c|}{ CMV-AU } & \multicolumn{2}{|c|}{ Controls } \\
\hline & & Cen & Tel & $\mathbf{n}$ & $(\%)$ & $\mathbf{n}$ & $(\%)$ \\
\hline$A A$ & 0 & $A A$ & $A A$ & 63 & 51.6 & 115 & 55.3 \\
\hline \multirow{8}{*}{$B x$} & \multirow{2}{*}{1} & $A A$ & $A B$ & 26 & 21.3 & 45 & 21.6 \\
\hline & & $A B$ & $A A$ & 8 & 6.6 & 20 & 9.6 \\
\hline & \multirow{3}{*}{2} & $A A$ & $B B$ & 2 & 1.6 & 5 & 2.4 \\
\hline & & $A B$ & $A B$ & 17 & 13.9 & 14 & 6.7 * \\
\hline & & $B B$ & $A A$ & 1 & 0.8 & 1 & 0.5 \\
\hline & \multirow{2}{*}{3} & $A B$ & $B B$ & 2 & 1.6 & 4 & 1.9 \\
\hline & & $B B$ & $A B$ & 3 & 2.5 & 2 & 1 \\
\hline & 4 & $B B$ & $B B$ & 0 & 0 & 2 & 1 \\
\hline
\end{tabular}

CMV-AU, $n=122$; Healthy controls, $n=208$ [25].Assignment of $A / B$ KIR haplotype motifs and calculation of $B$ content scores followed the method described by Cooley et al. [31]. ${ }^{*} p=0.049$, Odds Ratio $2.24,95 \%$ confidence interval (CI) 1.06-4.73.

KIR function is dependent on the presence/absence of the cognate HLA class I as its ligand; therefore, we characterized the HLA class I allotype groups (HLA-C groups 1 and 2 and $H L A-B$ Bw4-positive HLA-B alleles; details in the Methods section) that were assumed to serve as KIR ligands in the CMV-AU cases. The frequencies of these KIR ligand groups in the CMV-AU group did not differ significantly compared with those in the healthy control group (Table 2). However, when the HLA-B allotypes were compared, allotypes with isoleucine at position 80 (80Ile) were over 3 times more frequent than the alternative threonine (80Thr) at this position in the CMV-AU group (80Ile/80Thr ratio: CMV-AU 3.1 vs. control 0.90 ). This is of importance from the perspective of NK cell reactivity because engagement of HLA-B molecules with 80Ile results in significantly stronger signaling through the cognate KIR3DL1 receptor [19,32]. 
Table 2. Frequency of KIR ligands in CMV-AU and healthy controls.

\begin{tabular}{|c|c|c|c|c|c|c|c|}
\hline & \multicolumn{2}{|c|}{ CMV-AU } & \multicolumn{2}{|c|}{ Controls } & \multirow{2}{*}{$P$} & & \\
\hline & $\mathbf{n}$ & $\%$ & $\mathbf{n}$ & $\%$ & & & \\
\hline $\mathrm{C} 1^{+}$ & 118 & 99.2 & 206 & 99 & n.s. & & \\
\hline \multirow[t]{3}{*}{$\mathrm{C} 2^{+}$} & 27 & 22.7 & 45 & 21.6 & n.s. & & \\
\hline & \multicolumn{2}{|c|}{ CMV-AU } & \multicolumn{2}{|c|}{ Controls } & $P$ & $\mathrm{OR}$ & $95 \% \mathrm{CI}$ \\
\hline & $\mathbf{n}$ & $\%$ & $\mathbf{n}$ & $\%$ & & & \\
\hline$H L A-B B w 4^{+}$ & 69 & 59.5 & 122 & 58.7 & n.s. & & \\
\hline $80 \mathrm{Ile}^{+}$ & 54 & 46.6 & 63 & 30.3 & 0.0058 & 1.94 & $1.23-3.1$ \\
\hline $80 T h r_{+}$ & 17 & 14.7 & 70 & 33.7 & 0.0007 & 0.38 & $0.21-0.67$ \\
\hline ratio of $80 \mathrm{Ile} / 80 \mathrm{Thr}$ & & 3.1 & & 0.9 & & & \\
\hline
\end{tabular}

CMV-AU, HLA-C $n=119$, HLA-B $n=116$; healthy controls, $n=208$ [25]. n.s.; no significance. OR; Odds Ratio.

Associations between CMV-AU and KIR polymorphisms were also identified. KIR allotypes differ in cell surface expression levels, inhibitory capacity, and licensing $[13,17,19,33]$. To enable better assessment of the potential for KIR polymorphisms in driving the pathogenesis of anterior uveitis, we compared KIR allotype frequencies between CMV-AU and CMV-seropositive healthy control cohorts (Table 3). Here, we identified seven KIR3DL1 alleles in these two cohorts and found that $86 \%$ of CMV-AU and CMV-seropositive controls had high expression alleles of KIR3DL1 (KIR3DL1H) (Table 4). This was significant because KIR3DL1H allotypes have been demonstrated to confer strong NK cell licensing in combination with HLA-B Bw4 80Ile [19,32]. Overall, the genetic analyses indicated a substantial presence of strong inhibitory KIR-HLA interactions in the CMV-AU cohort.

Table 3. KIR3DL1 allele-level genotypes in CMV-AU patients and CMV-seropositive healthy controls.

\begin{tabular}{|c|c|c|c|c|c|c|}
\hline \multirow{2}{*}{$\begin{array}{c}\text { KIR3DL1 } \\
\text { (1st Allele) }\end{array}$} & \multirow{2}{*}{$\begin{array}{c}\text { KIR3DL1 } \\
\text { (2nd Allele) }\end{array}$} & \multirow[t]{2}{*}{ Phenotypes } & \multicolumn{2}{|c|}{ CMV-AU } & \multicolumn{2}{|c|}{ CMV-IgG ${ }^{+}$Controls } \\
\hline & & & $\mathbf{n}$ & $\%$ & $\mathbf{n}$ & $\%$ \\
\hline $3 D L 1 * 001$ & $3 D L 1 * 01502$ & $\mathrm{HH}$ & 6 & 4.9 & 2 & 4.7 \\
\hline $3 D L 1 * 01502$ & $3 D L 1^{*} 01502$ & $\mathrm{HH}$ & 21 & 17.2 & 15 & $34.9 *$ \\
\hline $3 D L 1 * 01502$ & $3 D L 1 * 020$ & $\mathrm{HH}$ & 2 & 1.6 & 0 & 0 \\
\hline $3 D L 1^{*} 01502$ & $3 D L 1 * 029$ & $\mathrm{HH}$ & 2 & 1.6 & 0 & 0 \\
\hline $3 D L 1 * 020$ & $3 D L 1 * 001$ & $\mathrm{HH}$ & 0 & 0 & 1 & 2.3 \\
\hline $3 D L 1 * 001$ & $3 D L 1 * 00501$ & HL & 3 & 2.5 & 2 & 4.7 \\
\hline $3 D L 1^{*} 00501$ & $3 D L 1^{*} 01502$ & HL & 23 & 18.9 & 5 & 11.6 \\
\hline $3 D L 1 * 00501$ & $3 D L 1 * 02901$ & $\mathrm{HL}$ & 2 & 1.6 & 0 & 0 \\
\hline $3 D L 1 * 00701$ & $3 D L 1 * 01502$ & HL & 11 & 9 & 3 & 7 \\
\hline $3 D L 1 * 00701$ & $3 D L 1^{*} 020$ & HL & 1 & 0.8 & 0 & 0 \\
\hline $3 D L 1 * 01502$ & $3 D L 1 * 008$ & $\mathrm{HL}$ & 0 & 0 & 1 & 2.3 \\
\hline $3 D L 1 * 01502$ & $N$ & $\mathrm{H}$ & 29 & 23.8 & 7 & 16.3 \\
\hline $3 D L 1 * 020$ & $N$ & $\mathrm{H}$ & 2 & 1.6 & 1 & 2.3 \\
\hline $3 D L 1 * 029$ & $N$ & $\mathrm{H}$ & 3 & 2.5 & 0 & 0 \\
\hline
\end{tabular}


Table 3. Cont.

\begin{tabular}{|c|c|c|c|c|c|c|}
\hline \multirow{2}{*}{$\begin{array}{c}\text { KIR3DL1 } \\
\text { (1st Allele) }\end{array}$} & \multirow{2}{*}{$\frac{\text { KIR3DL1 }}{\text { (2nd Allele) }}$} & \multirow[t]{2}{*}{ Phenotypes } & \multicolumn{2}{|c|}{ CMV-AU } & \multicolumn{2}{|c|}{ CMV-IgG ${ }^{+}$Controls } \\
\hline & & & $\mathbf{n}$ & $\%$ & $\mathbf{n}$ & $\%$ \\
\hline $3 D L 1^{*} 00501$ & $3 D L 1 * 00501$ & LL & 2 & 1.6 & 0 & 0 \\
\hline $3 D L 1^{*} 00501$ & $3 D L 1^{*} 00701$ & LL & 1 & 0.8 & 0 & 0 \\
\hline $3 D L 1 * 00701$ & $3 D L 1^{*} 00701$ & LL & 1 & 0.8 & 2 & 4.7 \\
\hline $3 D L 1^{*} 00501$ & $N$ & $\mathrm{~L}$ & 7 & 5.7 & 3 & 7 \\
\hline $3 D L 1 * 00701$ & $N$ & $\mathrm{~L}$ & 1 & 0.8 & 0 & 0 \\
\hline $3 D L 1 * 00501$ & $3 D L 1 * 038$ & $\mathrm{~L} ?$ & 1 & 0.8 & 0 & 0 \\
\hline$N$ & $N$ & & 4 & 3.3 & 1 & 2.3 \\
\hline
\end{tabular}

CMV-AU, $n=122 ;$ CMV-IgG $^{+}$(seropositive) healthy controls, $n=43$. H: high, L: low, N: absent, ?: undetermined. $* p=0.02$, Odds Ratio: $0.4,95 \%$ CI: $0.17-0.85$.

Table 4. Frequency of individuals carrying KIR3DL1H alleles in the CMV-AU and CMV-seropositive control cohorts.

\begin{tabular}{ccccc}
\hline & \multicolumn{3}{c}{ CMV-AU } & \multicolumn{2}{c}{ CMV-IgG $^{+}$Healthy Controls } \\
\cline { 2 - 5 } & $\mathbf{n}$ & \% & $\mathbf{n}$ & \% \\
\hline KIR3DL1H $^{+}$ & 105 & 86.1 & 37 & 86 \\
\hline
\end{tabular}

CMV-AU, $n=122$; CMV-IgG $^{+}$(seropositive) healthy controls, $n=43$.

2.2. Identification of Four NK Cell Subsets Distinguished by Differential Expression of CD57 and KLRG1: Expansion of $C D 57^{+} \mathrm{KLRG1} 1^{-}$and $\mathrm{CD} 57^{+} \mathrm{KLRG1}{ }^{+} \mathrm{NK}$ Cell Populations in $C M V$-Seropositive Individuals

We investigated the known CMV-related markers in the NK cell populations in individuals carrying the genetic background of HLA-B Bw4 80Ile and KIR3DL1H. CD57, NKG2C, and specific KIRs were markers of interest as previous studies have demonstrated that CMV infection induces expansion of NK cells expressing them. In particular, Beziat et al. reported that NK cells expressing inhibitory KIRs that recognize self-ligands (self-iKIR) are often selectively expanded during CMV infection [34]. CD57 is also an established marker for terminally differentiated human NK cells and has been used to assess immunological senescence. In contrast, KLRG1, which is considered a maturation marker in rodent NK cells, is not regarded to be a maturation marker in human NK cells [35].

High-dimensional flow cytometric analysis of NK cells in CMV-AU and CMV-seropositive healthy individuals revealed the existence of four distinct subsets distinguished by various combinations of CD57 and KLRG1 expression as follows: CD57 single positive (CD57 SP), CD57/KLRG1 double positive (DP), KLRG1 single positive (KLRG1 SP), and CD57/KLRG1 double negative (DN) subsets (Figure 2a,b). Importantly, these four subsets expressed different levels of NKG2A and NKG2C, implying that they are functionally distinct. The NK cell profiles in CMV-AU cases tended to differ from those of the CMV-seropositive healthy individuals, with the CD57/KLRG1 DP subset present at the highest frequency in the CMV-AU cohort ( $47 \%$, 7 of 15 individuals) and the CD57SP subset present at the highest frequency in the CMV-seropositive healthy individuals ( $47 \%, 8$ of 17 individuals) (Figure 2c). 
(a)

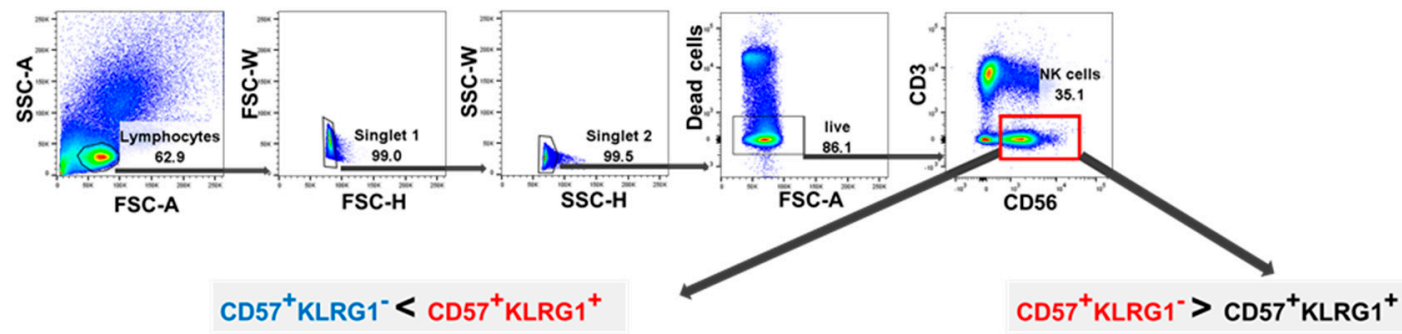

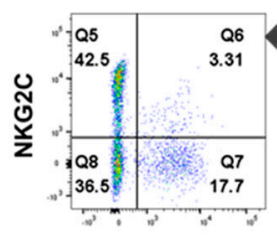
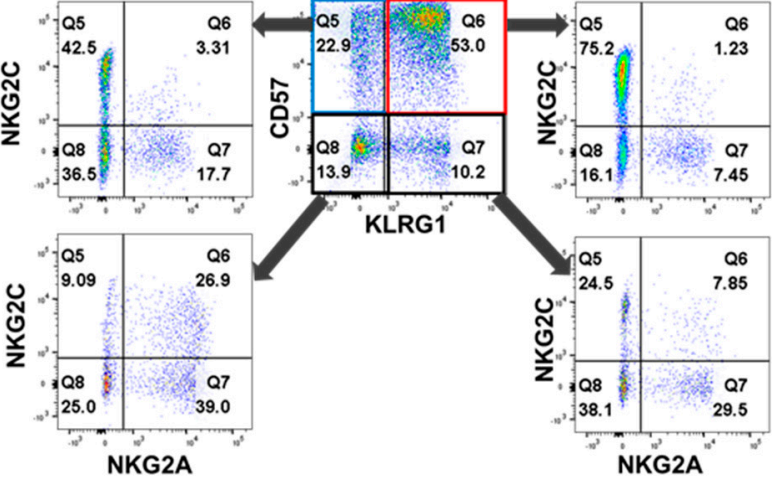

(b)

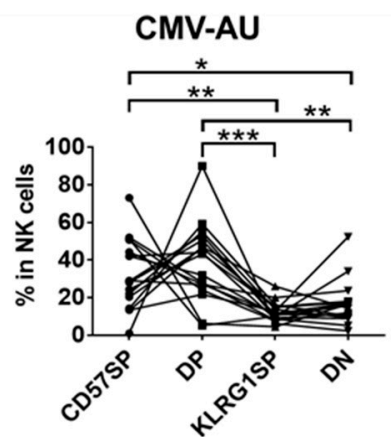

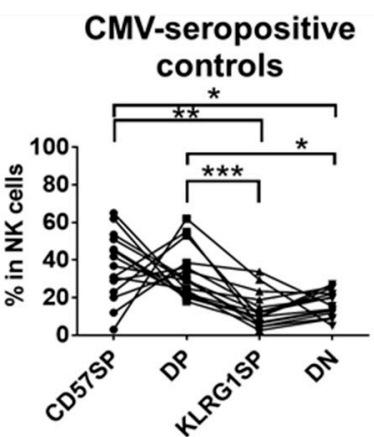

(c)

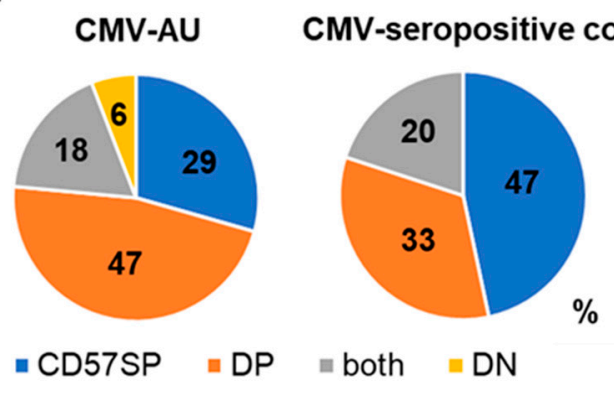

Figure 2. Expansion of the $\mathrm{CD} 57^{+} \mathrm{KLRG} 1^{-}$or the $\mathrm{CD} 57^{+} \mathrm{KLRG} 1^{+}$subsets among the four natural killer (NK) cell subsets distinguished by the differential expression of CD57 and KLRG1. (a) Identification of four NK cell subsets as determined by differential expression of CD57 and KLRG1. Representative profiles of two CMV-seropositive healthy individuals with expansion of either the $\mathrm{CD} 57^{+} \mathrm{KLRG}^{+}$or $\mathrm{CD} 57^{+} \mathrm{KLRG} 1^{-} \mathrm{NK}$ subset. Notably, NKG2A and NKG2C are expressed at different levels on each subset. (b) Frequencies of the four NK subsets are shown for each individual. ANOVA: CMV-AU, $p=0.0025$; CMV-seropositive controls, $p=0.002$. ${ }^{*} p<0.05,{ }^{* *} p<0.01,{ }^{* * *} p<0.001$. (c) The proportions of NK cell subsets most expanded in the CMV-AU and CMV-seropositive healthy individuals. CMV-AU: $n=17, \mathrm{CMV}$-seropositive controls: $n=15$.

\subsection{CD57/KLRG1 DP Subset Expansion in CMV-AU Individuals with HLA-B Bw4 80Ile and KIR3DL1H}

We next investigated the potential influence of the presence of self-ligands for inhibitory KIRs on the NK cell profiles in the CMV-AU cohort. Having identified that KIR3DL1H alleles combine with strong HLA-B Bw4 allotypes as a feature of the genetic background in CMV-AU, we investigated the CD57/KLRG1 NK cell phenotypes in association with CMV-AU cases with this background. As shown in Figure 3a, we observed a significant expansion of the CD57/KLRG1 DP population in $71.4 \%$ of patients carrying HLA-B Bw4 80Ile and KIR3DL1H. In contrast, the CD57SP population was the most frequent (44-50\%) in the CMV-seropositive controls, regardless of whether or not the individuals carried HLA-B Bw4 80Ile and KIR3DL1H. Furthermore, the ratio of CD57/KLRG1 DP NK cell population was significantly higher among the KIR3DL1-expressing NK cells in CMV-AU individuals carrying HLA-B Bw4 80Ile and KIR3DL1H compared to the CMV- 
seropositive controls (Figure 3b). These results imply an interesting profile of NK cells in the CMV-AU cohort where the CD57/KLRG1 DP NK cell population has apparently expanded in patients carrying a genetic background of $H L A-B$ Bw4 80Ile and KIR3DL1H alleles.

(a)
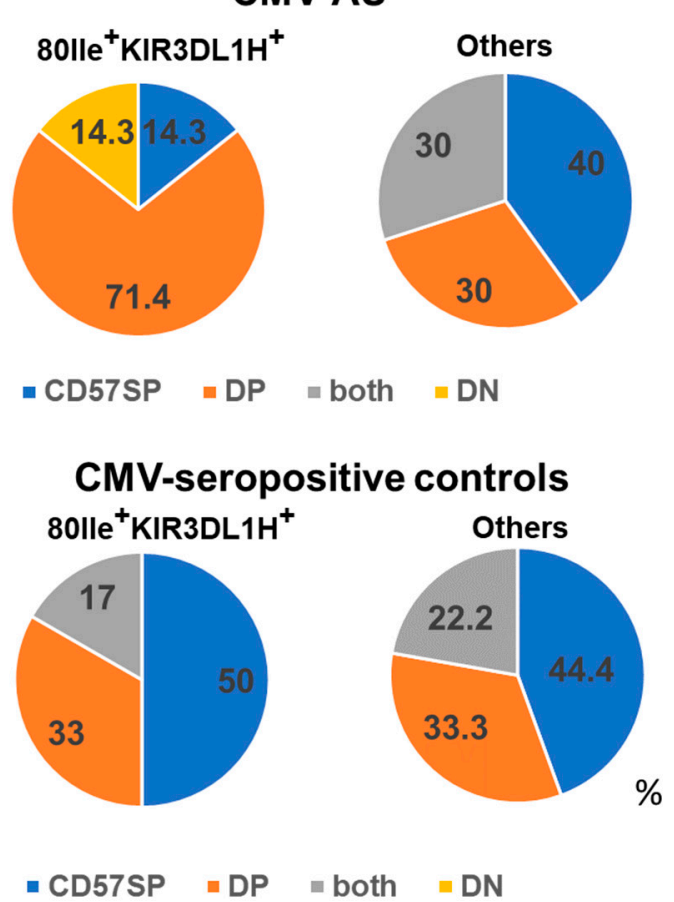

(b)

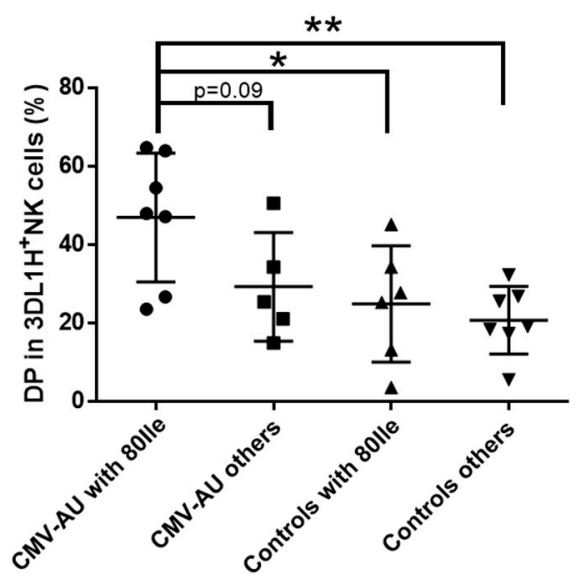

Figure 3. Expansion of CD57/KLRG1 DP NK cells in CMV-AU patients carrying HLA-B Bw4 80Ile and KIR3DL1H. (a) The proportion of expanded NK cell subsets among CMV-AU patients and CMV-seropositive healthy individuals in the presence or absence of HLA-B Bw4 80Ile and KIR3DL1H (CMV-AU, $n=17$; CMV-seropositive controls, $n=15$ ). (b) Distributions of $\mathrm{KIR}_{3} \mathrm{DL} 1 \mathrm{H}^{+} \mathrm{NK}$ cells among the CD57/KLRG1 subsets. CD57/KLRG1 DP subset frequencies among KIR3DL1H ${ }^{+} \mathrm{NK}$ cells were significantly elevated in CMV-AU patients carrying HLA-B Bw4 80Ile as compared to CMV-seropositive controls (CMV-AU, $n=12$; CMV-seropositive controls, $n=13$; ANOVA $p=0.0097)$. Data represent the mean+ standard deviation. ${ }^{*} p<0.05,{ }^{* *} p<0.01$.

\subsection{Differential Expression of NKG2C and iKIRs in CD57SP and DP NK Subsets}

We then sought to understand the implications of the NK cell profiles in our cohorts. We found significant elevation of NKG2C expression on the CD57/KLRG1 DP subset both in CMV-AU patients and CMV-seropositive controls (Figure 4a). As NKG2C directly recognizes a CMV virus protein and induces expansion of NKG2C-expressing NK cells, expansion of the CD57/KLRG1 DP subset in CMV-AU is likely due to the strong activation induced by CMV-infected cells [21,22,36,37]. In contrast, no difference was observed in the frequencies of $\mathrm{CD} 57^{+} \mathrm{NKG} 2 \mathrm{C}^{+}, \mathrm{CD}^{2} 7^{+}$, and $\mathrm{NKG} 2 \mathrm{C}^{+} \mathrm{NK}$ cells between $\mathrm{CMV}-\mathrm{AU}$ and CMV-seropositive controls (Figure $4 b$ ). 
(a)
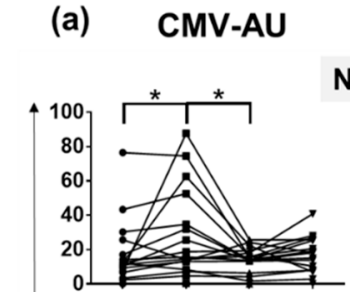

NKG2C
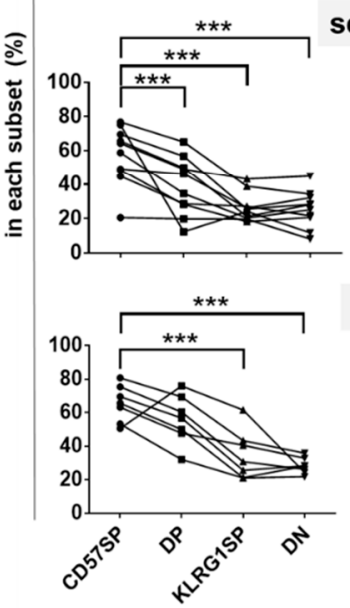

iKIR
CMV-seropositive controls

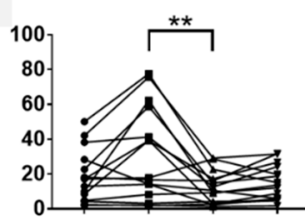

self-iKIR
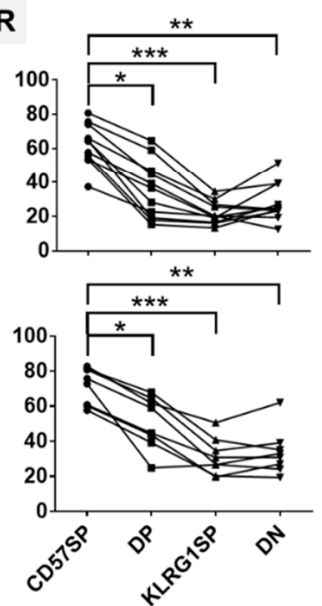

(b)
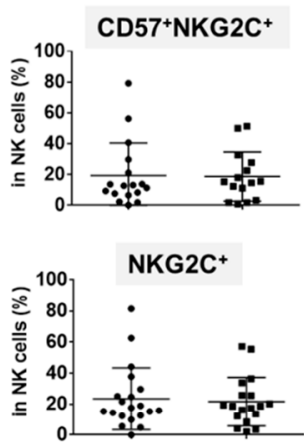

$\mathrm{CD} 57^{+}$

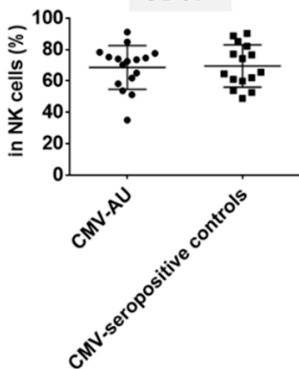

Figure 4. The four NK cell subsets defined by differential expression of CD57 and KLRG1 express disparate levels of NKG2C and iKIR. (a) Proportion of cells expressing NKG2C and iKIR on the four NK cell subsets. (CMV-AU, $n=15$; CMV seropositive controls, $n=17$. ANOVA: NKG2C, $p=0.047$; self-iKIR, $p=0.0001$; iKIR, $p=0.0006$. Linear trend test: self-iKIR \& iKIR, $p<0.0001) .{ }^{*} p<0.05$, ${ }^{* *} p<0.01,{ }^{* * *} p<0.001$. (b) Proportion of CD57 ${ }^{+} \mathrm{NKG} 2 \mathrm{C}^{+}, \mathrm{NKG}^{*} \mathrm{C}^{+}, \mathrm{CD}^{*} 7^{+} \mathrm{NK}$ cells in CMV-AU and $\mathrm{CMV}$-seropositive healthy individuals $\left(\mathrm{CD} 57^{+} \mathrm{NKG}^{2} \mathrm{C}^{+}, \mathrm{CD}^{+} 7^{+}\right.$: CMV-AU, $n=17$; CMV-seropositive controls, $n=15$; NKG2C ${ }^{+}$: CMV-AU, $n=20$; CMV-seropositive controls, $n=18$ ). Data represent the mean \pm standard deviation.

We also identified distinct expression patterns of self-iKIRs on CD57/KLRG1 subsets. Among the CD57/KLRG1 subsets, the CD57SP subset had the highest frequency of cells expressing self-iKIRs followed by the CD57/KLRG1 DP subset, KLRG1 SP subset, and the CD57/KLRG1 DN subset in both CMV-seropositive healthy controls and CMV-AU (Figure 4a).

\section{Discussion}

To the best of our knowledge, this is the first study investigating immunological factors in CMV-AU. The individuals tended to carry KIR3DL1 and HLA-B allotypes encoding strong inhibitory receptor-ligand interactions, and our findings show substantial presence of NK cell populations in these cases co-expressing CD57 and KLRG1 receptors in conjunction with the receptor NKG2C that binds the CMV UL40 virus protein.

CMV is known to downregulate HLA-B expression on infected cells. This leads to the induction of NK cell missing-self responses in the KIR3DL1-expressing NK cell subsets, especially in donors carrying both the HLA-B Bw4 80Ile and KIR3DL1H allotypes. These allotype combinations are one of those that have been demonstrated to confer strong NK cell licensing [19,32].

CMV also modulates expression of multiple HLA class I moieties as an escape mechanism from both $\mathrm{T}$ cell and NK cell immunity. In this context, $\mathrm{T}$ cell escape is achieved by inducing downregulation of classical HLA class I [20]; however, this has the potential to trigger NK cell missing-self responses depending on the HLA allotypes of the host. As a possible means to effectively escape NK cell responses in this situation, the virus induces upregulation of the non-classical HLA class I molecule, HLA-E. Previous studies have shown that this process is mediated by enhancing the loading of HLA-E molecules with 
peptides derived from the virus UL40 protein [22]. The HLA-E:UL40 peptide complex is then recognized by the inhibitory NK cell receptor, NKG2A, to inhibit NK cell responses.

HLA-E is also recognized by the activating NK cell receptor, NKG2C. In this study, NKG2C was expressed mainly on the expanded CD57/KLRG1 DP subset. Thus, we hypothesize that NKG2C expression on the CD57/KLRG1 DP subset has facilitated recognition of CMV-infected cells.

The previous reports that have described inhibitory KIR co-expression in the CD57 ${ }^{+} \mathrm{NKG} 2 \mathrm{C}^{+} \mathrm{NK}$ cell populations expanded in CMV-seropositive individuals prompted us to investigate composite KIR and HLA genetics in our CMV-AU cases [34,38,39]. In this study, we identified KIR3DL1H allotypes in donors carrying strong HLA-B allotypes (80Ile), which led to our hypothesis for strong KIR-ligand interactions playing a role in the pathogenesis of CMV-AU, possibly as a result of enhanced activation induced by missing-self responses.

It is noteworthy that the high expression allotypes of KIR3DL1 and HLA-B allotypes with 80Ile polymorphisms are both present at higher frequencies in East Asian as compared to Caucasian populations [7,13,40-42], corresponding to the global distribution of CMV-AU.

We also identified significantly higher expression of iKIRs on CD57SP NK cells compared to CD57/KLRG1 DP subsets. During NK cell development, immature NK cells are known to express HLA-specific receptors at different stages, where NKG2A is expressed exclusively in stage 4 and iKIR expression follows thereafter in stage 5 [43]. This implies that the CD57SP NK subset expanded in our CMV-seropositive controls displays a more mature phenotype compared to the CD57/KLRG1 DP subset expanded in CMV-AU patients. We speculate that the potential difference in maturation status of the expanded NK subset in CMV-AU patients compared with asymptomatic CMV-seropositive controls could be an additional factor contributing to the pathogenesis of CMV-AU.

Polymorphisms of KIRs and their ligands have been associated with various clinical issues in CMV infection. Patients with symptomatic, primary CMV infection tend to carry allotypes of HLA-B that serve as a weaker ligand (80Thr allotypes) for KIR3DL1 [44]. These patients also tended to be homozygous for the group $A$ KIR haplotypes (that carry KIR3DL1), implicating NK cell inhibition through KIR3DL1 interactions as a mode of pathogenesis. Compared with healthy controls, our analyses showed a contrasting genetic background where CMV-AU cases tended to carry heterozygous combinations of group $A$ and $B K I R$ haplotypes, rather than being homozygous for group $A K I R$ haplotypes (high frequencies of the Cen $A / B+\operatorname{Tel} A / B$ haplotype block combinations). These KIR genotypes encode a balanced mix of inhibitory and activating KIR in these cases. Thus, we hypothesize that CMV-AU may have a different mechanism of pathogenesis compared to symptomatic primary CMV infection.

Studies have indicated that the presence of more activating KIR genes (encoded primarily in the KIR B haplotypes) is protective against CMV reactivation in hematopoietic stem cell transplantation, implying potent roles of activating KIRs and NK cells in controlling CMV reactivation [45-47]. Given the prevalence of KIR B haplotypes (encoding more activating KIRs) and the expansion of the CD57/KLRG1 DP NK cell subset (co-expressing NKG2C and KIR3DL1H) in CMV-AU patients with the HLA-B Bw4 80Ile allotypes, our current hypothesis is that the higher gene dose of activating KIR in CMV-AU cases results in dysregulated activation of the CMV-specific NKG2C-expressing NK cell subsets.

Neither the CMV-AU patients nor the CMV-seropositive healthy individuals displayed extraocular symptoms that have been hitherto associated with CMV infection in general, such as colitis and hepatitis. Recent studies have also inferred an association with CMV-seropositivity and increased prevalence of cardiovascular diseases and increased morbidity/mortality in elderly populations [48]. In our cohort, the CMV-AU patients did not seem to manifest CMV-associated symptoms other than in the eye; however, it will be of interest to screen for CMV-induced changes (some of which may be subclinical), and especially in the context of aging and tissue senescence, and the risks as a consequence of these conditions. A second point of importance as a feature of CMV-AU is that the 
inflammation is apparently limited to the intraocular space-an immune-privileged site. This observation begs the question whether other immune-privileged tissues similarly develop inflammation in CMV-AU cases. This remains an unanswered question in this pilot study.

Although many studies have employed the use of animal models to investigate CMVinduced disease, we intentionally limited our approach to the analyses of clinical specimens in this study. It is difficult to study clinical isolates of human CMV in other species due to host specificity, and also due to virus instability caused by the high rate of virus mutations that occur in in vitro cultures. The AD169 laboratory strain of human CMV has been often used in immunological studies; however, this strain was unsuitable for our study as it lacks the genes related to evasion from NK cell responses. Therefore, it will be important to test our hypothesis on the immunological modes of CMV-AU pathogenesis in a suitable model, once a viable platform is developed.

\section{Materials and Methods}

\subsection{Human Subjects}

One hundred and twenty-two Chinese Singaporean patients diagnosed as CMV-AU by PCR analysis of aqueous humor samples were recruited at the Singapore National Eye Centre from 2014 to 2017. Whole blood samples were collected from CMV-AU patients and genomic DNA was extracted using the Nucleon BACC Genomic DNA Extraction kit (GE Healthcare Life Sciences, MA, USA) according to the manufacturer's instructions. Samples collected from $43 \mathrm{CMV}$-seropositive Chinese Singaporean healthy donors without ocular inflammation served as healthy controls in KIR3DL1 allele analyses. Peripheral blood mononuclear cells (PBMCs) were isolated by Ficoll gradient separation from $20 \mathrm{CMV}$ AU (mean age 62 (43-81) years old) and 18 CMV-seropositive healthy controls (mean age 58 (37-76) years old) and compared for NKG2C expression on NK cells. Seventeen CMV-AU and $15 \mathrm{CMV}$-seropositive healthy controls were compared for differences in NK cell repertoires.

This study was conducted in accordance with the Declaration of Helsinki and was approved by the SingHealth Institutional Review Board. Written informed consent was received from all participants.

\subsection{KIR Genotyping, KIR3DL1 Allele Typing and KIR Ligand Typing}

PCR-based sequence-specific primer typing (PCR-SSP) for sixteen KIR genes was performed in 122 CMV-AU individuals with primer sets as described by Vilches et al. [49]. PCR was conducted using $0.2 \mu \mathrm{L}$ of Platinum Taq polymerase (Thermo Fisher Scientific, Carlsbad, CA, USA) in $12 \mu \mathrm{L}$ PCR reactions at $3.8 \mathrm{mM}$ of $\mathrm{MgCl}_{2}$ and $150 \mathrm{ng}$ genomic DNA as previously described [50]. The PCR conditions were initial denaturation for $2 \mathrm{~min}$ at $95^{\circ} \mathrm{C}$, then 10 cycles of $10 \mathrm{sec}$ at $94{ }^{\circ} \mathrm{C}$ and $40 \mathrm{sec}$ at $65^{\circ} \mathrm{C}$ and 20 cycles of $20 \mathrm{sec}$ at $94{ }^{\circ} \mathrm{C}, 20 \mathrm{sec}$ at $61{ }^{\circ} \mathrm{C}$ and $30 \mathrm{sec}$ at $72{ }^{\circ} \mathrm{C}$, final extension of $7 \mathrm{~min}$ at $72{ }^{\circ} \mathrm{C}$. All reactions were conducted using thermal cycler PE9700 (Applied Biosystems, Foster city, CA, USA). KIR ligand types were determined by typing HLA-B and $C$ loci using a commercial system (Capture HLATM protocol and Assign MPS; Conexio Genomics, Perth, Australia) in 119 CMV-AU. Typing for HLA-B failed in three individuals. KIR3DL1 ligands (HLA-B alleles with the Bw4 motif) were classified into 80Ile and 80Thr groups by amino acids at position 80. HLA-C alleles were classified into group 2 (C2) and group 1 (C1) as cognate ligands for KIR2DL1 and KIR2DL3, respectively [18]. Centromeric $A / B$ and telomeric $A / B K I R$ motifs were assigned according to the presence or absence of $B$ KIR haplotype-specific KIR genes in centromeric/telomeric KIR haplotype motifs according to Cooley et al. [31]. KIR3DL1 alleles were determined by next-generation sequencing (NGS) using a commercial system (Illumina MiSeq combined with the KIR IGS system; Scisco Genetics, Seattle, WA, USA) [51]. 


\subsection{Antibodies and Flow Cytometry}

The following monoclonal antibodies were used for flow cytometric analysis: antiCD56 (B159), anti-CD3 (SK7), anti-KIR2DL2/3/2DS2 (GL183), anti-CD57 (NK-1) (BD Biosciences, San Jose, CA, USA), anti-KIR3DL1 (DX9), anti-NKG2A (REA110), anti-KLRG1 (REA261), anti-KIR2DS4 (JJC1.6), anti-NKG2C (REA205) (Miltenyi Biotech, Bergisch Gladbach, Germany), and anti-KIR2DL1 (Cl143211) (R\&D Systems, Minneapolis, MN, USA). Dead cells were excluded using LIVE/DEAD Fixable Dead Cell Staining kits (Thermo Fisher Scientific) according to the manufacturer's instructions. After staining of PBMCs with LIVE/DEAD Fixable Dead Cell Stain for $10 \mathrm{~min}$ at room temperature, PBMCs were washed and stained with the antibody mixture for $30 \mathrm{~min}$ on ice. PBMCs were fixed with BD Cytofix (BD Biosciences) and analyzed by 11-parameter flow cytometry using a LSR Fortessa cell analyzer (BD Biosciences). Flow cytometry data were analyzed using FlowJo software (Tree Star, Ashland, OR, USA). Expanded NK subsets were defined by a more than 1.5-fold increase in frequency compared against other subsets. The frequencies of inhibitory KIRs in NK subsets were calculated in group $A$ homozygotes to exclude activating KIRs recognized by anti-KIR2DL2/3/2DS2 mAbs.

\subsection{Statistical Analysis}

Data were statistically analyzed using Prism software (GraphPad Software; San Diego, CA, USA). KIR gene and KIR ligand frequencies were compared with healthy individuals of the same ethnicity (Chinese Singaporean, $n=208$, unknown CMV-serostatus) in a previous study using Fisher's exact test [25]. The CMV-seropositivity of the healthy controls was assumed to be more than $87 \%$, based on a previous study [26]. Mann-Whitney tests were used for comparisons between two groups. Repeated-measures one-way ANOVA with Dunnett's multiple comparison test was used for multiple comparisons between NK cell subsets. Linear trend tests were conducted for the analysis of receptor expression on NK subsets. $p$-values $<0.05$ were considered statistically significant.

\section{Conclusions}

A mechanism of overly active CMV-specific NK cells is proposed in CMV-AU pathogenesis where NK cells with CMV-reactive phenotypes (co-expression of CD57, KLRG1, NKG2C) are expanded upon a genetic background encoding strong KIR-HLA interactions.

Author Contributions: Conceptualization, N.Y. and J.S.; methodology, N.Y. and M.Y.; validation, N.Y. and M.S.; formal analysis, N.Y. and M.S.; investigation, N.Y., M.S., K.W., X.L., H.T., and J.S.; resources, J.S., S.-P.C., and M.Y.; data curation, N.Y. and J.S.; writing-original draft preparation, N.Y. and M.S.; writing—review and editing, M.Y., J.S., Y.-I.K., H.T., S.-P.C., and K.-H.S.; visualization, M.S. and N.Y.; supervision, N.Y. and J.S.; project administration, N.Y. and J.S.; funding acquisition, J.S., N.Y., and K.-H.S. All authors have read and agreed to the published version of the manuscript.

Funding: This research was funded by the National Medical Research Council, Singapore, grant number NMRC/TA/010/2012, NMRC/CNIG/1113/2013, Singapore National Eye Centre Health Research Endowment Fund, grant number R1043/58/2013, Singhealth Foundation Research Grant, grant number SHF/FG487S/2010, Japanese Society for the Promotion of Science (JSPS), grant number 17H07303, 18K09467, and Japan Agency for Medical Research and Development (AMED), grant number JP20jk0210029.

Institutional Review Board Statement: The study was conducted according to the guidelines of the Declaration of Helsinki, and approved by the SingHealth Centralised Institutional Review Board A (Protocol No: R786/70/2010 and R1043/58/2013 and dates of approval 14 July 2011 and 30 July 2013 respectively).

Informed Consent Statement: Informed consent was obtained from all subjects involved in the study.

Data Availability Statement: The data presented in this study are available in this article.

Conflicts of Interest: The authors declare no conflict of interest in this study. The funders had no role in the design of the study; in the collection, analyses, or interpretation of data; in the writing of the manuscript, or in the decision to publish the results. 


$\begin{array}{ll}\text { Abbreviations } \\ \text { CMV } & \text { Cytomegalovirus } \\ \text { CMV-AU } & \text { CMV-associated anterior uveitis } \\ \text { NK cells } & \text { natural killer cells } \\ \text { KIRs } & \text { Killer cell Immunoglobulin-like Receptors } \\ \text { PBMC } & \text { Peripheral blood mononuclear cells } \\ \text { PCR-SSP } & \text { PCR-based sequence-specific primer typing }\end{array}$

\section{References}

1. Picarda, G.; Benedict, C.A. Cytomegalovirus: Shape-Shifting the Immune System. J. Immunol. 2018, 200, 3881-3889. [CrossRef]

2. Berry, R.; Watson, G.M.; Jonjic, S.; Degli-Esposti, M.A.; Rossjohn, J. Modulation of innate and adaptive immunity by cytomegaloviruses. Nat. Rev. Immunol. 2020, 20, 113-127. [CrossRef]

3. Bastidas-Legarda, L.Y.; Khakoo, S.I. Conserved and variable natural killer cell receptors: Diverse approaches to viral infections. Immunology 2019, 156, 319-328. [CrossRef]

4. Sugar, E.A.; Jabs, D.A.; Ahuja, A.; Thorne, J.E.; Danis, R.P.; Meinert, C.L.; Studies of the Ocular Complications of AIDS Research Group. Incidence of cytomegalovirus retinitis in the era of highly active antiretroviral therapy. Am. J. Ophthalmol. 2012, 153, 1016-1024. [CrossRef] [PubMed]

5. Chee, S.P.; Bacsal, K.; Jap, A.; Se-Thoe, S.Y.; Cheng, C.L.; Tan, B.H. Clinical features of cytomegalovirus anterior uveitis in immunocompetent patients. Am. J. Ophthalmol. 2008, 145, 834-840. [CrossRef]

6. $\quad$ Koizumi, N.; Suzuki, T.; Uno, T.; Chihara, H.; Shiraishi, A.; Hara, Y.; Inatomi, T.; Sotozono, C.; Kawasaki, S.; Yamasaki, K.; et al. Cytomegalovirus as an etiologic factor in corneal endotheliitis. Ophthalmology 2008, 115, 292-297. [CrossRef] [PubMed]

7. Chan, N.S.; Chee, S.P.; Caspers, L.; Bodaghi, B. Clinical Features of CMV-Associated Anterior Uveitis. Ocul. Immunol. Inflamm. 2018, 26, 107-115. [CrossRef] [PubMed]

8. Sonoda, K.H.; Hasegawa, E.; Namba, K.; Okada, A.A.; Ohguro, N.; Goto, H.; Group, J.U.S.W. Epidemiology of uveitis in Japan: A 2016 retrospective nationwide survey. Jpn. J. Ophthalmol. 2021, 65, 184-190. [CrossRef] [PubMed]

9. Chee, S.P.; Jap, A. Cytomegalovirus anterior uveitis: Outcome of treatment. Br. J. Ophthalmol. 2010, 94, 1648-1652. [CrossRef]

10. Chee, S.P.; Jap, A. Presumed fuchs heterochromic iridocyclitis and Posner-Schlossman syndrome: Comparison of cytomegaloviruspositive and negative eyes. Am. J. Ophthalmol. 2008, 146, 883-889. [CrossRef]

11. Orange, J.S. Natural killer cell deficiency. J. Allergy Clin. Immunol. 2013, 132, 515-525. [CrossRef]

12. Biron, C.A.; Byron, K.S.; Sullivan, J.L. Severe herpesvirus infections in an adolescent without natural killer cells. N. Engl. J. Med. 1989, 320, 1731-1735. [CrossRef]

13. Yawata, M.; Yawata, N.; Draghi, M.; Little, A.M.; Partheniou, F.; Parham, P. Roles for HLA and KIR polymorphisms in natural killer cell repertoire selection and modulation of effector function. J. Exp. Med. 2006, 203, 633-645. [CrossRef] [PubMed]

14. Karre, K.; Ljunggren, H.G.; Piontek, G.; Kiessling, R. Selective rejection of H-2-deficient lymphoma variants suggests alternative immune defence strategy. Nature 1986, 319, 675-678. [CrossRef] [PubMed]

15. Anfossi, N.; Andre, P.; Guia, S.; Falk, C.S.; Roetynck, S.; Stewart, C.A.; Breso, V.; Frassati, C.; Reviron, D.; Middleton, D.; et al. Human NK cell education by inhibitory receptors for MHC class I. Immunity 2006, 25, 331-342. [CrossRef]

16. Kim, S.; Poursine-Laurent, J.; Truscott, S.M.; Lybarger, L.; Song, Y.J.; Yang, L.; French, A.R.; Sunwoo, J.B.; Lemieux, S.; Hansen, T.H.; et al. Licensing of natural killer cells by host major histocompatibility complex class I molecules. Nature 2005, 436, 709-713. [CrossRef] [PubMed]

17. Yawata, M.; Yawata, N.; Draghi, M.; Partheniou, F.; Little, A.M.; Parham, P. MHC class I-specific inhibitory receptors and their ligands structure diverse human NK-cell repertoires toward a balance of missing self-response. Blood 2008, 112, $2369-2380$. [CrossRef]

18. Parham, P. MHC class I molecules and KIRs in human history, health and survival. Nat. Rev. Immunol. 2005, 5, 201-214. [CrossRef]

19. Boudreau, J.E.; Mulrooney, T.J.; le Luduec, J.B.; Barker, E.; Hsu, K.C. KIR3DL1 and HLA-B Density and Binding Calibrate NK Education and Response to HIV. J. Immunol. 2016, 196, 3398-3410. [CrossRef] [PubMed]

20. Schust, D.J.; Tortorella, D.; Seebach, J.; Phan, C.; Ploegh, H.L. Trophoblast class I major histocompatibility complex (MHC) products are resistant to rapid degradation imposed by the human cytomegalovirus (HCMV) gene products US2 and US11. $J$. Exp. Med. 1998, 188, 497-503. [CrossRef]

21. Tomasec, P.; Braud, V.M.; Rickards, C.; Powell, M.B.; McSharry, B.P.; Gadola, S.; Cerundolo, V.; Borysiewicz, L.K.; McMichael, A.J.; Wilkinson, G.W. Surface expression of HLA-E, an inhibitor of natural killer cells, enhanced by human cytomegalovirus gpUL40. Science 2000, 287, 1031-1033. [CrossRef]

22. Heatley, S.L.; Pietra, G.; Lin, J.; Widjaja, J.M.; Harpur, C.M.; Lester, S.; Rossjohn, J.; Szer, J.; Schwarer, A.; Bradstock, K.; et al. Polymorphism in human cytomegalovirus UL40 impacts on recognition of human leukocyte antigen-E (HLA-E) by natural killer cells. J. Biol. Chem. 2013, 288, 8679-8690. [CrossRef] [PubMed]

23. Guma, M.; Angulo, A.; Vilches, C.; Gomez-Lozano, N.; Malats, N.; Lopez-Botet, M. Imprint of human cytomegalovirus infection on the NK cell receptor repertoire. Blood 2004, 104, 3664-3671. [CrossRef] 
24. Rolle, A.; Brodin, P. Immune Adaptation to Environmental Influence: The Case of NK Cells and HCMV. Trends Immunol. 2016, 37, 233-243. [CrossRef] [PubMed]

25. Shen, M.; Linn, Y.C.; Ren, E.C. KIR-HLA profiling shows presence of higher frequencies of strong inhibitory KIR-ligands among prognostically poor risk AML patients. Immunogenetics 2016, 68, 133-144. [CrossRef]

26. Wong, A.; Tan, K.H.; Tee, C.S.; Yeo, G.S. Seroprevalence of cytomegalovirus, toxoplasma and parvovirus in pregnancy. Singap. Med. J. 2000, 41, 151-155.

27. Yawata, M.; Yawata, N.; Abi-Rached, L.; Parham, P. Variation within the human killer cell immunoglobulin-like receptor (KIR) gene family. Crit. Rev. Immunol. 2002, 22, 463-482. [CrossRef]

28. Hsu, K.C.; Chida, S.; Geraghty, D.E.; Dupont, B. The killer cell immunoglobulin-like receptor (KIR) genomic region: Gene-order, haplotypes and allelic polymorphism. Immunol. Rev. 2002, 190, 40-52. [CrossRef] [PubMed]

29. Yawata, M.; Yawata, N.; McQueen, K.L.; Cheng, N.W.; Guethlein, L.A.; Rajalingam, R.; Shilling, H.G.; Parham, P. Predominance of group A KIR haplotypes in Japanese associated with diverse NK cell repertoires of KIR expression. Immunogenetics 2002, 54, 543-550. [CrossRef]

30. Jiang, K.; Zhu, F.M.; Lv, Q.F.; Yan, L.X. Distribution of killer cell immunoglobulin-like receptor genes in the Chinese Han population. Tissue Antigens 2005, 65, 556-563. [CrossRef]

31. Cooley, S.; Weisdorf, D.J.; Guethlein, L.A.; Klein, J.P.; Wang, T.; Le, C.T.; Marsh, S.G.; Geraghty, D.; Spellman, S.; Haagenson, M.D.; et al. Donor selection for natural killer cell receptor genes leads to superior survival after unrelated transplantation for acute myelogenous leukemia. Blood 2010, 116, 2411-2419. [CrossRef]

32. Carrington, M.; Martin, M.P.; van Bergen, J. KIR-HLA intercourse in HIV disease. Trends Microbiol. 2008, 16, 620-627. [CrossRef] [PubMed]

33. Gardiner, C.M.; Guethlein, L.A.; Shilling, H.G.; Pando, M.; Carr, W.H.; Rajalingam, R.; Vilches, C.; Parham, P. Different NK cell surface phenotypes defined by the DX9 antibody are due to KIR3DL1 gene polymorphism. J. Immunol. 2001, 166, $2992-3001$. [CrossRef] [PubMed]

34. Beziat, V.; Liu, L.L.; Malmberg, J.A.; Ivarsson, M.A.; Sohlberg, E.; Bjorklund, A.T.; Retiere, C.; Sverremark-Ekstrom, E.; Traherne, J.; Ljungman, P.; et al. NK cell responses to cytomegalovirus infection lead to stable imprints in the human KIR repertoire and involve activating KIRs. Blood 2013, 121, 2678-2688. [CrossRef] [PubMed]

35. Sun, J.C.; Beilke, J.N.; Lanier, L.L. Adaptive immune features of natural killer cells. Nature 2009, 457, 557-561. [CrossRef] [PubMed]

36. Guma, M.; Budt, M.; Saez, A.; Brckalo, T.; Hengel, H.; Angulo, A.; Lopez-Botet, M. Expansion of CD94/NKG2C ${ }^{+}$NK cells in response to human cytomegalovirus-infected fibroblasts. Blood 2006, 107, 3624-3631. [CrossRef]

37. Lopez-Botet, M.; Muntasell, A.; Vilches, C. The CD94/NKG2C ${ }^{+}$NK-cell subset on the edge of innate and adaptive immunity to human cytomegalovirus infection. Semin. Immunol. 2014, 26, 145-151. [CrossRef]

38. Lopez-Verges, S.; Milush, J.M.; Schwartz, B.S.; Pando, M.J.; Jarjoura, J.; York, V.A.; Houchins, J.P.; Miller, S.; Kang, S.M.; Norris, P.J.; et al. Expansion of a unique $\mathrm{CD} 7^{+} \mathrm{NKG} 2 \mathrm{C}^{\text {hi }}$ natural killer cell subset during acute human cytomegalovirus infection. Proc. Natl. Acad. Sci. USA 2011, 108, 14725-14732. [CrossRef]

39. Manser, A.R.; Scherenschlich, N.; Thons, C.; Hengel, H.; Timm, J.; Uhrberg, M. KIR Polymorphism Modulates the Size of the Adaptive NK Cell Pool in Human Cytomegalovirus-Infected Individuals. J. Immunol. 2019, 203, 2301-2309. [CrossRef]

40. Leffell, M.S.; Cherikh, W.S.; Land, G.; Zachary, A.A. Improved definition of human leukocyte antigen frequencies among minorities and applicability to estimates of transplant compatibility. Transplantation 2007, 83, 964-972. [CrossRef]

41. Deng, Z.; Zhen, J.; Zhu, B.; Zhang, G.; Yu, Q.; Wang, D.; Xu, Y.; He, L.; Lu, L. Allelic diversity of KIR3DL1/3DS1 in a southern Chinese population. Hum. Immunol. 2015, 76, 663-666. [CrossRef]

42. Norman, P.J.; Abi-Rached, L.; Gendzekhadze, K.; Korbel, D.; Gleimer, M.; Rowley, D.; Bruno, D.; Carrington, C.V.; Chandanayingyong, D.; Chang, Y.H.; et al. Unusual selection on the KIR3DL1/S1 natural killer cell receptor in Africans. Nat. Genet. 2007, 39, 1092-1099. [CrossRef] [PubMed]

43. Freud, A.G.; Caligiuri, M.A. Human natural killer cell development. Immunol. Rev. 2006, 214, 56-72. [CrossRef] [PubMed]

44. di Bona, D.; Scafidi, V.; Plaia, A.; Colomba, C.; Nuzzo, D.; Occhino, C.; Tuttolomondo, A.; Giammanco, G.; de Grazia, S.; Montalto, G.; et al. HLA and killer cell immunoglobulin-like receptors influence the natural course of CMV infection. J. Infect. Dis. 2014, 210, 1083-1089. [CrossRef] [PubMed]

45. van Duin, D.; Avery, R.K.; Hemachandra, S.; Yen-Lieberman, B.; Zhang, A.; Jain, A.; Butler, R.S.; Barnard, J.; Schold, J.D.; Fung, J.; et al. KIR and HLA interactions are associated with control of primary CMV infection in solid organ transplant recipients. Am. $J$. Transplant. Off. J. Am. Soc. Transplant. Am. Soc. Transplant. Surg. 2014, 14, 156-162. [CrossRef]

46. Gonzalez, A.; Schmitter, K.; Hirsch, H.H.; Garzoni, C.; van Delden, C.; Boggian, K.; Mueller, N.J.; Berger, C.; Villard, J.; Manuel, O.; et al. KIR-associated protection from CMV replication requires pre-existing immunity: A prospective study in solid organ transplant recipients. Genes Immun. 2014, 15, 495-499. [CrossRef]

47. Cook, M.; Briggs, D.; Craddock, C.; Mahendra, P.; Milligan, D.; Fegan, C.; Darbyshire, P.; Lawson, S.; Boxall, E.; Moss, P. Donor KIR genotype has a major influence on the rate of cytomegalovirus reactivation following T-cell replete stem cell transplantation. Blood 2006, 107, 1230-1232. [CrossRef] 
48. Savva, G.M.; Pachnio, A.; Kaul, B.; Morgan, K.; Huppert, F.A.; Brayne, C.; Moss, P.A.; The Medical Research Council Cognitive Function and Ageing Study. Cytomegalovirus infection is associated with increased mortality in the older population. Aging Cell 2013, 12, 381-387. [CrossRef]

49. Vilches, C.; Castano, J.; Gomez-Lozano, N.; Estefania, E. Facilitation of KIR genotyping by a PCR-SSP method that amplifies short DNA fragments. Tissue Antigens 2007, 70, 415-422. [CrossRef]

50. Yawata, N.; Selva, K.J.; Liu, Y.C.; Tan, K.P.; Lee, A.W.; Siak, J.; Lan, W.; Vania, M.; Arundhati, A.; Tong, L.; et al. Dynamic change in natural killer cell type in the human ocular mucosa in situ as means of immune evasion by adenovirus infection. Mucosal Immunol. 2016, 9, 159-170. [CrossRef]

51. Nelson, W.C.; Pyo, C.W.; Vogan, D.; Wang, R.; Pyon, Y.S.; Hennessey, C.; Smith, A.; Pereira, S.; Ishitani, A.; Geraghty, D.E. An integrated genotyping approach for HLA and other complex genetic systems. Hum. Immunol. 2015, 76, 928-938. [CrossRef] [PubMed] 